\title{
Reflexões sobre diferentes abordagens do conceito de signo linguístico
}

\section{Reflections on different approaches to the concept of linguistic sign}

Eliane Wojslaw

\begin{abstract}
Resumo: Neste texto pretende-se refletir sobre diferentes conceitos de signo linguístico a partir das teorias do signo de Saussure, de 1916, de Peirce, do final do século XIX e de Bakhtin, do final da década de 20. Para tanto, apresenta-se um breve histórico dos estudos da linguagem até a proposição da ciência linguística, em 1916, por Saussure, e a mudança do foco dos estudos para os fatos linguísticos. Desenvolve-se uma reflexão sobre estes conceitos de signo com base nos conceitos de dicotomia vs. tricotomia; o sistema vs. a linguagem, e o formal vs. o social. O objetivo do artigo é ampliar o entendimento do conceito de signo linguístico, pois considera-se que este conceito é fundamental para o aprofundamento dos estudos da linguagem e seus diversos campos de estudo.

Palavras-chave: Signo. Significado. Linguagem.

Abstract: This article reflects about the different concepts of linguistic sign based on the sign theories proposed by Saussure in 1916; by Peirce in the end of $19^{\text {th }}$ century and by Bakhtin in the end the twenties. For this purpose, it is presented a brief history of language studies until the proposition of the Linguistics by Saussure in 1916, and the consequent change of the focus of the studies to linguistic facts. The paper also presents reflections about these three theoretical approaches of sign based on the concepts of dichotomy and trichotomy; system and language; formal and social aspects. The aim of the article is to broaden the understanding of the concept of linguistic sign as it is considered fundamental to furthering the study of language and its various fields of study.

Keywords: Sign. Meaning. Language.
\end{abstract}

\section{Introdução}

A partir da leitura de diferentes abordagens e teorias do signo, verbais e não verbais, delimitou-se este estudo em relação a três autores, considerando-se o seu respectivo momento na linha do tempo de estudos da linguagem, a saber:

Profa. Ms. Eliane Wojslaw, docente dos cursos superiores de Administração de Empresas, Relações Internacionais na Faculdade Anglo Americano e Secretariado Executivo Trilíngue na Faculdade União das Américas em Foz do Iguaçu - PR - E-mail: elianew @uniamerica.br. 
Saussure (1916), Peirce (final do século XIX) e Bakhtin (no final dos anos 20). $\mathrm{O}$ motivo da escolha destes autores se deve ao fato de que eles influenciaram de modo significativo as teorias do signo e pesquisas linguísticas posteriores.

Dittrich (2003) registra em seu artigo "Linguística: uma história de tensão entre o natural e o social", que a história da Linguística e seu objeto de estudo oscilam entre o estudo de aspectos naturais e sistêmicos, internos à linguagem, e o estudo de aspectos sociais e contextuais, externos à linguagem. Os aspectos naturais (internos) da linguagem referem-se à estrutura e aos sistemas de funcionamento dos mecanismos linguísticos. Por sua vez, os aspectos sociais (externos) referem-se ao contexto social em que está inserida a linguagem, ou seja, os aspectos sócio-econômicos, culturais, políticos, étnicos, psicológicos, cognitivos, entre outros (DITTRICH, 2003, p. 186).

O mesmo autor observa ainda que nesta dinâmica não há substituição de um conhecimento em detrimento do outro, mas uma interação entre estes e consequente construção de algo novo. Há um redizer das teorias anteriores pelas teorias mais atuais. "Não se trata necessariamente de um movimento dialético; trata-se antes, de relacionar aspectos próximos entre o antigo e o novo, integrando-os." (DITTRICH, 2003, p. 186).

Esta variação de paradigmas dos estudos linguísticos pode ser observada através das diferentes concepções de linguagem ao longo da história da Linguística. Neste sentido, observa-se também que os conceitos de signo lingüístico, segundo as teorias de Saussure, Peirce e Bakhtin, seguem esta lógica, ou seja, há uma mudança do foco estrutural e sistêmico para o foco social. Contudo, pode-se inferir que as propostas destes três autores se complementam na medida em que promovem diferentes olhares para um mesmo objeto.

\section{Breve histórico dos estudos da linguagem}

$\mathrm{O}$ interesse do homem em estudar a linguagem é muito antigo, os primeiros estudos de que se tem registro remontam ao século IV a.C. e referem-se a análises de textos sagrados hindus. Nesta mesma época, gramáticos hindus, a exemplo de Panini (século IV a.C.), preocuparam-se em descrever em detalhes a sua língua. Estes documentos somente foram descobertos pelo Ocidente no 
Reflexões sobre diferentes abordagens do conceito de signo.

século XVIII e serviram de base para novos estudos da linguagem. (PETTER, 2005, p. 12).

Foram os gramáticos gregos os primeiros a se preocuparem com a palavra e seu significado e a tentar entender se há uma relação entre a palavra e o conceito ou ideia a que esta remete. Aristóteles, na Grécia antiga, "chegou a elaborar a teoria da frase, a distinguir as partes do discurso e a enumerar as categorias gramaticais" (PETTER, 2005, p. 12).

Platão, apud Valene (1997, p. 36), na obra Crátilo - sobre a justeza dos nomes, já refletia sobre signo linguístico através do diálogo entre Sócrates, Hermógenes e Crátilo. O diálogo de Platão intitulado Crátilo demonstra que as ideias iniciais dos gregos sobre a utilização da palavra, o ato de dar nomes a pessoas e coisas e seu significado, influenciaram os pensadores contemporâneos na formulação de suas teorias do signo linguístico.

$\mathrm{Na}$ Idade Média, um grupo denominado de modistas defendia que existe uma estrutura gramatical universal a todas as línguas, contudo, o que pode variar são as regras gramaticais. No século XVI, a partir da Reforma Protestante, houve necessidade de que a Bíblia fosse traduzida para diversas línguas, apesar de o latim ser a língua considerada universal na época. Houve também, nessa época, uma intensificação das viagens exploratórias, de relações comerciais e diplomáticas entre países. Devido a esta intensificação, diversas línguas, até então desconhecidas, foram difundidas pelo mundo (PETTER, 1997, p. 13).

Foi somente a partir dos séculos XVII e XVIII que as ideias e reflexões estabelecidas na antiguidade tiveram continuidade. Foi lançada em 1660 a Grammaire Générale et Raisonée de Port Royal, conhecida até hoje como Gramática de Port Royal ou lógica clássica. Os autores desta gramática clássica, Lancelot e Arnaud, inspiraram o surgimento de grande parte das gramáticas contemporâneas. Esses autores afirmavam que a linguagem é uma faculdade da razão e, portanto, reflete o pensamento do falante. Tal afirmação informa que isto acontece em todas as línguas, independentemente de sua estrutura gramatical (PETTER, 1997, p. 13).

O século XIX, devido à difusão de línguas outrora desconhecidas, é marcado pelo interesse na Gramática Comparada e na Linguística Histórica. Houve significativo avanço nos estudos da linguagem a partir do século XIX. Muito foi organizado e descoberto através dos estudos comparados 
de gramática neste período. Por meio de análises exaustivas das relações de semelhanças entre muitas das línguas europeias, chegou-se à conclusão que houve uma língua mãe de todas estas línguas, denominada indo-europeu. É importante ressaltar que não se tem registros escritos deste idioma hipotético, mas chegou-se ao indo-europeu através de estudos histórico-comparativos. (PETTER, 2005, p. 13).

No século XX, houve outro grande avanço nos estudos da linguagem, a partir da proposição da Linguística como ciência por Ferdinand Saussure, que a organizou e a diferenciou de outras ciências da antiguidade, a exemplo da Filosofia, Lógica e Retórica, e também focou seu objeto de estudo nos fatos da linguagem. (SAUSSURE, 2004).

O signo é um fato da linguagem. Valene (1997, p. 14) esclarece que a ciência geral dos signos denomina-se Semiologia, termo cunhado por Saussure, ou Semiótica, termo proposto por Peirce. "Saussure e Peirce foram contemporâneos e desenvolveram seus estudos no final do século XIX e início do século XX sem que um tomasse conhecimento da obra do outro. A obra de Saussure privilegia o signo verbal e a de Peirce, os signos não verbais." (VALENE, 1997, p. 14).

Ressalta-se que não existe intenção de se defender neste artigo uma determinada proposta, mas de se refletir sobre os conceitos dos diferentes autores que propuseram distintas teorias e abordagens.

\section{O signo linguístico de acordo com saussure}

De acordo com o Curso de Linguística Geral (2004, p. 80), obra que reúne anotações de um curso proferido por Sausurre em 1916, "o signo linguístico une não uma coisa a uma palavra mas um conceito a uma imagem acústica". Esta ideia sobre o conceito de signo foi publicada na primeira edição da referida obra.

Para Saussure (2004), o conceito reflete o que o objeto é em si, em termos gerais e universais; suas propriedades e características o diferem de outros objetos. Por exemplo, a palavra latina arbor exprime o conceito de "árvore". A partir da compreensão de um conceito, as pessoas associam-no a uma imagem acústica que representa mentalmente o som do objeto. Constata-se este fato 
Reflexões sobre diferentes abordagens do conceito de signo.

quando se pensa em um objeto mas não se move os lábios para pronunciá-lo, não se emite som algum, mas ocorre a representação mental deste objeto. Desta forma, a imagem acústica dos objetos vem antes das elocuções humanas. Saussure propôs que a imagem acústica de um objeto é também denominada de impressão psíquica ou empreinte. Portanto, a comunicação ocorre primeiro mentalmente para depois ser expressa verbalmente. Os signos são instrumentos de comunicação e representação dos objetos e da realidade. Assim, a comunicação humana passa por este processo de associação de ideias estabelecida a partir das imagens acústicas dos objetos (SAUSURRE, 2004, p. 80).

No Curso de Linguística Geral, encontra-se o seguinte a respeito do significado e do significante:

Propomo-nos a conservar o termo signo para designar o total e a substituir conceito e imagem acústica respectivamente por significado e significante; estes dois termos têm a vantagem de assinalar a oposição que os separa, quer entre si, quer do total que fazem parte. (SAUSURRE, 2004, p. 80).

Estes dois elementos - significante e significado - que constituem o signo para Saussure, "estão intimamente unidos e um reclama o outro" (SAUSSURE, 2004, p. 80). Além disto, são interdependentes, inseparáveis e psíquicos, ou seja, são assimilados pelo cérebro humano através de um vínculo de associação. Assim, não se deve entender o signo de forma simplista, como algo que une um objeto a um nome, mas um conceito associado a uma imagem acústica puramente mental.

\subsection{Princípios do signo linguístico de saussure}

O primeiro princípio do signo é ser arbitrário. "O laço que une o significante ao significado é arbitrário [...] o signo linguístico é arbitrário." (SAUSSURE, 2004, p. 81). Assim, o termo "cadeira" não está ligado a nenhuma sequência de sons que lembre este objeto, poderia ser representado por qualquer outra sequência de sons, arbitrariamente, segundo Saussure. Para este autor, o signo é quase sempre arbitrário, isto é, imotivado e não tem semelhança ou laço com o que se refere. Saussure acrescenta ainda que apenas parte dos signos que compõe uma língua é totalmente arbitrário. Existe uma 
outra parte destes signos que é relativamente arbitrária, alguns exemplos são: os números (dezesseis, dezessete, dezenove); nomes de árvores de frutas (pereira, macieira), animais filhotes (gatinho, peixinho), as onomatopeias (auau, miau).

$\mathrm{O}$ segundo princípio é o caráter linear do significante. Este princípio refere-se às relações associativas que os falantes fazem para formar novas palavras e frases. Por exemplo, a partir do aprendizado do verbo desfazer, uma pessoa pode intuir a existência de outros verbos tais como descolar, deslocar, descobrir, entre outros. Há também a possibilidade desta pessoa intuir e utilizar novos termos a partir desta mesma palavra, desfazer, como por exemplo fazer, refazer, contrafazer, entre outras. Quanto às frases, o mesmo princípio de substituição pode originar várias frases diferentes. Por exemplo, a partir da frase, Pedro pesca todos os dias, podem ser construídas novas frases como: 1. Pedro corre todos os dias; 2. Pedro corre aos sábados; 3 . Maria corre aos domingos, entre outras.

Neste sentido, Saussure explica que a língua processa sua estrutura em dois eixos: o eixo paradigmático e o eixo sintagmático. Saussure (2004, p. 143) explana que no eixo paradigmático os signos se relacionam por associações de semelhança de sentido. Cita-se, como exemplo, o signo lua, associa-se a sol, planeta, astro. Já no eixo sintagmático, os signos se relacionam por diferenças. Por exemplo, na frase A bela lua prateada, o signo lua relaciona-se por contraste com os demais signos da frase $a$, bela, prateada. Assim, conclui Saussure (2004), que os signos se constituem de sentido mediante relações associativas e opositivas.

Pode-se inferir que, de forma inconsciente, a mente humana se utiliza dos elementos diferentes que compõem um sintagma para formar outros. Este processo de associação se dá através da memória que constrói constantemente novas combinações sintagmáticas. Cita-se aqui a Gramática Gerativa de Chomsky, que foi proposta a partir destes princípios da teoria saussuriana. O Gerativismo advoga que o ser humano é geneticamente dotado da faculdade de gerar novas sentenças a partir de combinações sintagmáticas simples e esta geração é infinita. (LYONS, 1987).

Retornando ao Curso de Linguistica Geral, vê-se que o linguista não somente abre caminhos - que serão posteriormente alargados pelo linguista norte-americano Noam Chomsky - mas também propõe o entendimento de signo linguístico ao apresentar reflexões sobre o fenômeno da mutabilidade e imutabilidade do signo. Neste sentido, a referida obra, composta por anotações do mestre Saussure, esclarece que a sociedade herda a língua de gerações an- 
Reflexões sobre diferentes abordagens do conceito de signo.

teriores, portanto, um determinado estado da língua é um produto histórico. Afirma-se ainda que não é de suma importância a preocupação em descobrir as origens da linguagem e que o único objeto de estudo da Linguística real é a "vida normal e regular de um idioma já constituído". O autor acrescenta também que, devido à língua ser uma herança, não se pode modificá-la de uma hora para outra e suas mudanças ocorrem lentamente através das gerações pois as pessoas geralmente parecem satisfeitas com o seu idioma. (SAUSSURE, 2004, p. 86-87).

Conclui-se, por meio das afirmações de Saussure, que um novo signo, ou neologismo, para ser adotado e aceito por uma comunidade, precisaria ser por ela utilizado. É principalmente pelo uso de um signo por uma comunidade que este se torna parte do vocabulário de uma língua. Mas, Saussure defende que não está ao alcance de um indivíduo estabelecer um novo significante para nomear um objeto; esta escolha só pode ser feita através da força social. Ao mesmo tempo, segundo Saussure (2004, p. 85) não se consulta uma comunidade para se adotar um signo, pois este processo é intrínseco à característica da língua e a língua é uma regra livremente consentida e adotada por uma coletividade. (SAUSSURE, 2004, p. 85).

\section{O signo segundo peirce}

Peirce (1839-1914) propôs no final do século XIX a ciência Semiótica, conhecida como a teoria geral dos signos. De acordo com a Semiótica, a realidade é mediada pelos signos e somente por meio deles é que se tem acesso à realidade. Este autor define que "um signo, ou representamem, é aquilo que, sob certo aspecto ou modo, representa alguma coisa para alguém. Dirige-se a alguém, isto é cria na mente desta pessoa um signo equivalente ou mais desenvolvido." (PEIRCE, 1977, p. 46).

Para Peirce (1977, p. 46), um signo é um conceito que é composto por três elementos: o signo, o objeto e o interpretante, que pressupõem uma relação triádica, ou seja, um signo existe e tem sentido a partir de uma inter-relação entre estes três componentes.

Peirce (1977, p. 47) cita, como exemplo, a palavra "estrela", que é um signo. Ao ser analisada enquanto signo, "estrela" pode significar: 1. astro com luz própria; 2 . artista célebre; 3 . sorte. Assim, explica-se a lógica da 
relação triádica: a partir de um signo (astro com luz própria), uma pessoa vai criar em sua mente um objeto (artista célebre), que é um novo signo, que não é igual ao primeiro, mas contém parte de seu significado e por sua vez cria o interpretante (sorte), que é um terceiro signo e que contém a "ideia" inicial em si (PEIRCE, 1977, p. 47).

Os três elementos que compõem o signo estão ligados à ideia inicial, denominada de fundamento do representamen, que seria o elemento comum e presente nos três elementos da tríade. De acordo com Peirce, a criação de signos ocorre em um sistema de autogeração infinita e pressupõe o conhecimento do signo inicial. (PEIRCE, 1977, p. 47).

Peirce denomina, portanto, de tríade da semiose este conceito composto pelos elementos signo-objeto-interpretante e ressalta que o signo, para ser compreendido e interpretado, depende destes três elementos que são bastante diferentes entre si, mas que estão intrinsecamente relacionados. (PEIRCE, 1977, p. 51).

Segundo Peirce (1977), a realidade é o que determina ou impulsiona a produção de signos. O signo é o termo mediador, o meio para o conhecimento do objeto. Peirce considera o objeto o intermediador da realidade e do conhecimento humano. Conclui-se, então, que o objeto muda parcialmente o signo em alguma instância, em algum momento. Peirce, (1997, p. 47) assevera que:

O signo só pode representar o objeto e referir-se a ele. Não pode propiciar contato ou reconhecimento do objeto [...] pressupõe uma familiaridade com algo de sorte a veicular alguma informação adicional concernente a este algo.

Para complementar a tríade e o entendimento do signo, seguem mais detalhes do interpretante. "O signo cria algo na mente do intérprete, algo esse que foi também de maneira relativa e mediada, criada pelo objeto do signo, embora o objeto seja algo essencialmente diverso do signo" (PEIRCE apud SANTAELLA, 2000, p.35). Portanto, o interpretante é a parte do signo que o interpreta, de acordo com seu conhecimento de mundo e contexto, é aquele que completa o sentido do signo.

Peirce (1977, p. 52) divide os signos não verbais em três categorias: símbolos, índices e ícones. Estes são constituídos a partir da mesma lógica triádica. 
Reflexões sobre diferentes abordagens do conceito de signo.

O símbolo é um signo que se refere a um objeto e tem vida própria, ou seja, não depende dele para existir. É convencionado socialmente, por exemplo, a balança da justiça. $\mathrm{O}$ índice é um signo que se refere a um objeto e é afetado por ele, depende do objeto para ser entendido, por exemplo, uma "nuvem preta" é um índice de chuva. Por sua vez, o ícone é um signo que representa e é semelhante ao objeto, se refere a ele ou tem existência e significado próprio, por exemplo, uma estátua ou uma caricatura.

José Luís Fiorin (2004) cita como exemplo um signo bastante conhecido, praticamente universal: a cruz que simboliza o Cristianismo. Contudo, é preciso que o interpretante tenha conhecimento de mundo e do que é ser cristão para interpretá-lo.

Deste modo, a definição de Peirce aponta para a função mediadora do signo, entre objeto e interpretante, e que o interpretante é criado pelo próprio signo. $\mathrm{O}$ fato de Peirce propor um elemento a mais para conceituar signo, que é o interpretante, amplia-o perante o conceito de Saussure.

\section{O signo linguístico segundo bakhtin}

Bakhtin (1999) formula seu conceito de consciência a partir do conceito de ideologia. Para ele, a construção do inconsciente, base do pensamento humano, está relacionada à situação de classe ocupada pelo indivíduo. Para Bakhtin, é necessário que o homem tenha um segundo nascimento: o "nascimento social". A consciência do indivíduo é, assim, uma consciência com dimensão coletiva e não individual. O nascimento biológico não é suficiente para o homem, pois ele é um ser social. (BAKHTIN, 1999).

Bakhtin (1997, p. 345) argumenta que "quando não há palavras, não há língua, não pode haver relação dialógica." O dialogismo ou relação dialógica pressupõe a existência do outro e é para Bakhtin a base da linguagem humana. Considerar o diálogo é considerar o outro, o diferente, o contraditório, o antagônico. Bakhtin usa também o termo alteridade para viabilizar o entendimento da existência do outro. Este conceito leva a outro, o da constituição dos imprintings sociais, históricos e ideológicos que constituem o indivíduo. A partir daí, entende-se a enunciação como um acontecimento social entre dois sujeitos e a partir deste diálogo composto por vozes sociais, constrói-se a identidade do indivíduo. 
Bakhtin propõe o estudo da palavra como instrumento de análise da dimensão ideológica da consciência humana. Segundo ele, o signo linguístico é construído socialmente e transmite uma ideologia, presente na sua constituição. O teórico moscovita faz uma crítica aos estudos linguísticos centrados na ideia de constituição física do signo linguístico defendida por Saussure. Declara ainda que as palavras carregam conteúdos ideológicos e vivenciais do seres sociais. E o homem somente compreende as palavras e reage àquelas que despertam "ressonâncias ideológicas ou concernentes à vida" (BAKHTIN, 1999, p. 80). Portanto, pode-se dizer que o signo, para Bakhtin, é uma unidade linguística com valores ideológicos.

Bakhtin (1999, p. 79-80) diferencia signo de sinal. Para ele, o signo é compreendido e o sinal identificado. Os processos de compreensão e de identificação são distintos. O sinal não pertence ao mundo da ideologia, sendo apenas reconhecido; é imutável; já o signo deve ser compreendido e é carregado de conteúdo ideológico. Neste sentido, Bakhtin declara sobre o processo de compreensão, ou descodificação - que envolve o signo, o processo de identificação e o sinal:

O sinal é uma entidade de conteúdo imutável; ele não pode substituir, nem refletir, nem retratar nada; constitui apenas um instrumento técnico para designar este ou aquele objeto (preciso e imutável) ou este ou aquele acontecimento (igualmente preciso e imutável) [...]. O elemento que torna a forma linguística um signo não é sua identidade como sinal mas sua mobilidade específica. (BAKHTIN, 1999, p. 79-80).

A compreensão de língua, de linguagem e de signo linguístico de Saussure reflete o paradigma estruturalista, portanto, o signo é um sinal, é identificado em vez de ser compreendido, e seu entendimento ocorre na mente do falante (imagem acústica). Por outro lado, o signo linguístico de Bakhtin existe no contexto enunciativo e discursivo, fora dele é sinal e não signo e é compreendido pelo sujeito histórico social como algo imutável.

\section{Reflexões}

Apresentam-se, a seguir, algumas reflexões sobre as abordagens de signo linguístico propostas pelos três autores, Saussure, Peirce e Bakhtin. 
Reflexões sobre diferentes abordagens do conceito de signo.

\subsection{A dicotomia $v s$. a tricotomia}

A abordagem de Saussure (2004) é estruturalista e sistêmica e pode ser reconhecida em pelo menos quatro dicotomias apresentadas em sua teoria: 1. língua e fala; 2 . linearidade e arbitrariedade; 3 . sintagma e paradigma; 4. sincronia e diacronia.

Saussure dicotomizou também os elementos constituintes do signo linguístico em conceito e imagem acústica (ou significado/significante). $\mathrm{O}$ sentido do signo linguístico de Saussure se estabelece a partir das relações dos eixos sintagmáticos e paradigmáticos e suas combinações possíveis dentro de um sistema linguístico. Assim, observa-se que Saussure (2004), apesar de ter declarado que considera a língua um fato social, e ter dicotomizado seu estudo em língua e fala, respectivamente langue e parole, manteve seu foco na parte estrutural da língua, priorizando-a, não tendo aprofundado a parte da linguagem referente à parole, ou seja, à fala no contex to social.

Por sua vez, Peirce (1997) organizou a Semiótica ${ }^{1}$ ou ciência geral dos signos, e assevera que a realidade somente pode ser interpretada e o conhecimento pode ser construído a partir dos signos. Deste modo, Peirce (1997) criou um amplo sistema de organização de categorias e tipos de signos, constituído por três tricotomias e dez classes de signos. Peirce propõe um conceito de signo com três faces (signo/objeto/interpretante) e o sentido do signo advém da relação entre estes três elementos que são interdependentes. A abordagem deste autor é mais completa e amplia a proposta de Saussure, pois pressupõe a existência de uma pessoa externa que vai interpretar o signo de acordo com seu conhecimento de mundo.

Em resumo, segundo Peirce (1997), não se pode assimilar determinados signos se não se tem um modelo material para a construção mental. $\mathrm{O}$ referente é a imagem material externa. Quando alguém explica a outrem o que é um chip de computador sem este outrem ter visto um, ele pode entender o signo "chip de computador" apenas parcialmente. Este indivíduo tem também que ter assimilado previamente vários outros signos (computador, memória, tecnologia...) para entender este.

Quanto a Bakhtin, ressalta-se que este autor não utilizou os termos dicotomia e nem tricotomia, pois considerava o signo como multifacetado,

\footnotetext{
Saussure denominou esta ciência de Semiologia e propôs que a Linguística fosse um dos seus ramos de estudo. 
ou seja, dotado de valores sócio-histórico-ideológicos construídos através da interação social do indivíduo. Bakhtin (1999) considerava o sujeito enunciativo, emissor de um discurso polifônico, e, portanto, de signos compostos por várias vozes sociais.

\section{O sistema vs. a língua em uso; o formal vs. o social}

Travaglia (1996, p. 21-23) destaca três concepções de linguagem. A primeira considera a linguagem como expressão do pensamento monológico e individual. Nesta concepção se inserem os estudos linguísticos tradicionais que resultaram na gramática normativa e tradicional, na qual se presume que há regras e normas gramaticais a serem seguidas para a organização lógica do pensamento. Para esta concepção, segundo Travaglia (1996), a constituição do texto não depende em nada de: em que situação se fala, onde, como, quando e para quem se fala. Tem-se aqui a concepção formal da linguagem, ou seja, sistêmica.

A segunda concepção apresentada pelo autor considera a linguagem como instrumento e meio objetivo para a comunicação, na qual a língua é vista como um código, um conjunto de signos que se combinam segundo regras e do qual os falantes devem ter conhecimento. Para esta concepção, o falante que tem em mente uma mensagem a transmitir a um ouvinte deve ter também um código comum aos dois, proceder à emissão de ondas sonoras ou luminosas para que o receptor as decodifique. Esta concepção está representada pelo estruturalismo de Saussure e pelo transformacionismo (a partir de Chomsky). Tem-se aqui, novamente, a parte estrutural da língua, o sistema.

de interação:

A terceira concepção conceitua a linguagem como forma ou processo

O indivíduo, ao usar a língua não é tão somente traduzir e exteriorizar o pensamento ou transmitir informações a alguém, mas sim realizar ações, agir, atuar sobre o interlocutor (ouvinte-leitor). A linguagem é pois um lugar de interação humana, de interação comunicativa pela produção de efeitos de sentido entre interlocutores, em uma dada situação de comunicação e em um contexto sócio-histórico e ideológico. 
Reflexões sobre diferentes abordagens do conceito de signo.

Nesta terceira concepção estão incluídas as teorias da Semântica Argumentativa, Pragmática, Análise do Discurso, Linguística Textual, entre outros ramos de estudos linguísticos (TRAVAGLIA, 1996, p. 23). E, ainda, encontra-se a parte contextual e social da língua à qual se referia Dittrich (2003) no início deste artigo. Esta prosposta aproxima-se das ideias de Bakhtin sobre língua, linguagem e signos, pois pressupõem uma abordagem social. Para Bakhtin (1997) a língua é heterogênea e interativa, o signo é uma unidade linguística com valores ideológicos e sua teoria mostra-se aberta para a contextualização enunciativa e discursiva. De um lado, Saussure desenvolve suas ideias sobre o sistema linguístico estrutural e, de outro, Bakhtin desenvolve ideias sobre a enunciação, o contexto enunciativo, o sujeito sócio histórico e ideológico.

\section{Considerações finais}

A história da Linguística é a história da ampliação gradativa de seu objeto de estudo, desde as unidades mínimas (morfemas, fonemas, sintagmas) até as unidades mais amplas como o texto - estudado através da proposta da Linguística Textual e das condições de produção textual a partir do enunciado - enunciação.

O estudo do signo linguístico é básico e imprescindível para a compreensão da formação do pensamento humano e da linguagem, da construção do conhecimento e do ser humano social e ideológico.

A partir destas reflexões teóricas, considera-se que entre os três autores apresentados, Saussure, Peirce e Bakhtin, a proposta bakhtiniana é a mais ampla. A linguagem é um instrumento para expressar o pensamento de um sujeito histórico-social, permeado de uma ideologia, a qual mesmo inconsciente reflete um sujeito dialógico. A linguagem se modifica no diálogo com o outro e amolda-se a partir do contex to enunciativo. O pensamento, por sua vez, também se modifica com esta dinâmica. Um ajuda o outro e um não existe sem o outro.

Contudo, é necessário continuar este estudo de modo a aprofundar as reflexões sobre este conceito a partir de diálogos com outros autores e linhas teóricas, a exemplo da Linguística Textual, Pragmática e Análise do Discurso, entre outras.

Finaliza-se este artigo, retomando as reflexões de Dittrich (2003, p.192) sobre a interdisciplinaridade da linguagem: 
Assim, uma história da Linguística pensada como um movimento de continuidades e retomadas, em que duas tendências ora convivem, ora se seguem, contrapondo-se ou retomando-se, parece conforme com o próprio desenvolvimento desta ciência. Trata-se menos de uma luta de contrários por novas sínteses, e mais de um movimento contínuo em que ora um ora outro dos aspectos predomina.

Observa-se que os conceitos de signo acompanharam estes movimentos de rupturas, continuidades e retomadas ao longo da história da Linguística, pois é um conceito básico, o qual acompanha as tendências desta ciência, renova-se e amplia-se a partir de propostas mais atuais, mas sem abandonar as propostas anteriores que complementam o seu entendimento.

\section{Referências}

BAKHTIN, Mikhail. Estética da criação verbal. São Paulo: Martins Fontes, 1997.

Marxismo e filosofia da linguagem. São Paulo: Hucitec, 1999.

DITTRICH, Ivo José. Linguística: uma história de tensão entre o natural e o social. Revista Línguas e Letras. Cascavel: Edunioeste, 2003.

FIORIN, José Luiz. A teoria geral dos signos. In: FIORIN, José Luiz (Org.). Introdução à linguística: I. Objetos teóricos. São Paulo: Contexto, 2005.

LYONS, J. Linguagem e linguística: uma introdução. São Paulo: LTC, 1987.

LOPEZ, Débora Cristina; DITTRICH, Ivo José. A palavra como signo ideológico no discurso jornalístico. Disponível em: <www.bocc.ubi.pt/pag/lopez-debora-ivo-palavra-signo-ideologico.pdf $>$. Acesso em: 20 ago. 2006.

PEIRCE, Charles Sanders. Semiótica. São Paulo: Perspectiva, 1977.

PETTER, Margarida. Linguagem, língua, Linguística. In: FIORIN, José Luiz. Introdução à linguística: I. Objetos teóricos. São Paulo: Contexto, 2005.

PLATÃO. Diálogos - Teeteto - Crátilo. Belém: PA: Universidade Federal do Pará, 1988. v. 9. p. 119-194. SANTAELLA, Lucia. A Teoria Geral dos Signos: como as linguagens significam as coisas. São Paulo: Pioneira Thomson Learning, 2000.

SAUSSURE, Ferdinand. Curso de linguística geral. $26^{\mathrm{a}}$. ed. São Paulo: Pensamento-Cultrix, 2004.

SOUZA, João Ernandes de. O signo linguístico e a constituição de sentido. Disponível em: 〈www.agata.ucg.br>. Acesso em: 29 set. 2006. 
Reflexões sobre diferentes abordagens do conceito de signo.

TRAVAGLIA, Luiz Carlos. Gramática e interação: uma proposta para o ensino da gramática no $1^{\circ}$ e $2^{\circ}$ graus. São Paulo: Cortez, 1996.

VALENE, André. A linguagem nossa de cada dia. Rio de Janeiro: Leviatã Publicações, 1997.

Recebido para publicação em 21 jun. 2010. Aceito para publicação em 16 jul. 2010. 